\title{
Factors affecting final functional outcomes in open-globe injuries and use of ocular trauma score as a predictive tool in Nepalese population
}

\author{
Saurav M. Shrestha $a^{1,2^{*}}$ (D) Casey L. Anthony ${ }^{3}$, Grant A. Justin ${ }^{4,5}$, Madhu Thapa', Jyoti B. Shrestha ${ }^{1}$, Anadi Khatri ${ }^{6,7}$,
} Annette K Hoskin ${ }^{8,9}$ and Rupesh Agrawal ${ }^{10,11,12}$

\begin{abstract}
Background: Open globe injury (OGI) is one of the most devastating form of ocular trauma. The aim of the study is to identify the epidemiology and predict visual outcomes in traumatic open globe injuries using ocular trauma score (OTS) and correlate with final visual acuity (VA) at 3 months.

Methods: Patients older than 5 years, presenting to B.P. Koirala Lions Centre for Ophthalmic Studies (BPKLCOS) from March 2016- March 2017 with OGI that met inclusion criteria were evaluated. Patient profile, nature and cause of injury, and time to presentation were recorded. Patients were managed accordingly and followed up to 3 months. An OTS score for each patient was calculated and raw scores were categorized accordingly. The VA after 3 months were compared to the predicted OTS values.

Results: Seventy-three eyes of 72 patients were examined. $76 \%$ were male, and the mean age was 26.17 years (median, 23.5 years). The mean time from injury to presentation was $<6$ hours (30 patients, $41 \%$ ). Thirty-seven eyes $(51 \%)$ had zone I trauma, followed by twenty eyes (27\%) with zone II, and sixteen eyes (22\%) with zone III trauma. Sixty-five patients ( $90 \%)$ were managed surgically, and fifty (68\%) received intravitreal antibiotics with steroid. When compared, the projected VA as per OTS were able to predict actual final visual outcomes in $60 \%$ of the eyes with OGI of various zones.

Conclusions: OTS can be an accurate predictive tool for final visual acuity even with a short follow up period of 3 months; with poor presenting visual acuity, delayed presentation, posterior zones of injury, need for intravitreal injections, endophthalmitis, and globe rupture associated with poorer prognosis.
\end{abstract}

Keywords: BETTS, Ocular trauma, Ocular trauma score, OGI, Open Globe Injury, OTS

\footnotetext{
* Correspondence: saurav.stha1025@gmail.com

'B.P. Koirala Lions Centre for Ophthalmic Studies, Institute of Medicine,

Tribhuvan University Teaching Hospital, Kathmandu, Nepal

${ }^{2}$ Department of Vitreoretina, Mechi Eye Hospital, Birtamode, Nepal

Full list of author information is available at the end of the article
}

C C The Author(s). 2021 Open Access This article is licensed under a Creative Commons Attribution 4.0 International License, which permits use, sharing, adaptation, distribution and reproduction in any medium or format, as long as you give appropriate credit to the original author(s) and the source, provide a link to the Creative Commons licence, and indicate if changes were made. The images or other third party material in this article are included in the article's Creative Commons licence, unless indicated otherwise in a credit line to the material. If material is not included in the article's Creative Commons licence and your intended use is not permitted by statutory regulation or exceeds the permitted use, you will need to obtain permission directly from the copyright holder. To view a copy of this licence, visit http://creativecommons.org/licenses/by/4.0/ The Creative Commons Public Domain Dedication waiver (http://creativecommons.org/publicdomain/zero/1.0/) applies to the data made available in this article, unless otherwise stated in a credit line to the data. 


\section{Background}

Ocular trauma is one of the leading causes of ocular morbidity and monocular blindness in the world, with open globe injury (OGI) constituting a major portion of trauma related vision loss [1]. A loss of one eye equates to $24 \%$ of whole-body disability, increasing to $85 \%$ if the patient is bilaterally blind [2]. Hence, a major ocular injury can result in both severe physical damage and psychological trauma for patients and relatives. Approximately 750,000 cases of ocular trauma are hospitalized each year, with 203,000 open globe injuries per year worldwide [3, 4]. In Nepal, ocular trauma is the second leading cause of unilateral blindness after cataract, with 8.6/1,000 people having a history of ocular trauma [5]. Several studies have shown an increasing prevalence of ocular trauma with a bimodal distribution [6]. Males are six times more likely to be affected than females, and a recent report showed a shift from workplace to home as the place of injury [3, 7-11].

The prognosis of ocular injury cases, while varied, has improved in recent years due to the development of microsurgical and vitreoretinal techniques [10]; however, a historical lack of standard protocols and terminology made it difficult to appropriately triage and manage patients. The management of open globe injury is driven by a desire to achieve the best possible long-term visual outcome, and having prognostic information is important for triaging decisions and counseling a patient and their family. Functional prognosis following ocular injury varies widely with various risk factors associated with poorer visual outcomes [12-15].

The Birmingham Eye Trauma Terminology System (BETTS) is a widely accepted standardized system of categorizing ocular trauma terminologies that enables the accurate transmission of clinical information and study data $[16,17]$. The Ocular Trauma Score (OTS) is a simplified predictive tool for ocular trauma cases first described by Kuhn et al. in 2002 [4, 18]. It is based on BETTS and the features of globe injury at initial examination, with scores based on risk factors shown to be associated with visual outcomes. The score's predictive value is useful not only for counseling patients and families, but for managing expectations and guiding clinical decisions, particularly in resource-limited settings. Rationale for OTS being a reliable predictive tool would be valuable as the scoring system is classically used to predict the visual outcome of patients after 'open-globe ocular trauma' which by definition is a full thickness wound of the eye wall with the condition usually resulting to blindness [19]. Various studies have validated the OTS as a reliable predictive tool, with a predictive accuracy of up to $80 \%[20,21]$.

Multiple studies have reported a wide range of incidence of open globe injuries in diverse geographical settings, however only a few studies have addressed trauma including rural areas of developing country, and no studies have evaluated the extent of open globe injury with the use of OTS in this type of setting in Nepal [7]. This hospital-based prospective study, which was conducted at one of the tertiary eye care centers in Nepal, aims to characterize OGI in the region, identify risk factors, correlate with visual outcomes, and implement and test the predictive value of OTS as a standard tool for management of OGI.

\section{Methods}

A hospital-based prospective study was conducted at BPKLCOS under Tribhuvan University Teaching Hospital (TUTH) from March 2016- March 2017. This study received Institutional Review Board approval (Institute of Medicine, TUTH), and informed consent was obtained from each patient/ guardian and complied with the Tenets of the Declaration of Helsinki.

\section{Sample size and sampling technique}

Non- probability purposive sampling technique was used. All diagnosed cases of OGI, irrespective of gender, laterality, duration of presentation, and other chronic systemic illness, that presented to BPKLCOS and the TUTH emergency department between March 2016 March 2017 were included in the study. Patients with life-threatening conditions requiring life support, patients under 5 years of age, and those unwilling or unable to undergo ocular evaluations and investigations were excluded.

\section{Data collection}

Detailed history and clinical examination were conducted for all patients. History from the patient or guardian included: chief complaint, mode and agent of trauma, place of injury, time to presentation, treatment prior to hospital presentation, and past medical and surgical history. The eye examination included assessment of visual acuity using Snellen visual acuity chart, direct and consensual pupillary reaction/ Relative afferent pupillary defect (RAPD), periocular, anterior segment, and posterior segment examination. Extent and type of ocular injury was defined complying the BETTS terminologies and classifications [17]. Zones of injury were classified based on Ocular Trauma Classification Group, where Zone I injuries involves only the cornea, Zone II injuries extends from limbus to anterior $5 \mathrm{~mm}$ of sclera and Zone III injuries extends beyond $5 \mathrm{~mm}$ from limbus in sclera [22]. All patients received an orbital $\mathrm{x}$-ray and $\mathrm{A} / \mathrm{B}$ scan, as well as CT orbit/head when indicated.

Predicted visual outcome was calculated for each patient using Ocular Trauma Score $[4,18]$. On initial examination, a raw score depending on the initial visual 
acuity was assigned. The final score was calculated by subtracting points, according to presence or absence of various predefined variables, from the initial raw score. OTS variables includes Globe rupture, Endophthalmitis, Perforating injury, Retinal detachment (RD), and RAPD. The final score was matched to the relevant OTS group, ranging from 1 (most severe injury) to 5 (least severe injury) and are associated with a published range of predicted post-injury visual acuities, which correlates with an estimated probability of final visual acuity.

All patients were admitted to the eye ward of TUTH and managed surgically under general anesthesia as indicated. Intravitreal injections of Ceftazidime $(2.25 \mathrm{mg} /$ $0.1 \mathrm{ml})$, Vancomycin $(1 \mathrm{mg} / 0.1 \mathrm{ml})$ and Dexamethasone $(0.4 \mathrm{mg} / 0.1 \mathrm{ml})$ were administered in eyes with posterior segment involvement - either in terms of extension of the injury, inflammation or radiological findings from the B-scan. Patients were clinically evaluated a minimum of once daily for one week and followed up weekly for one month and monthly for three months. At the end of 3 months follow up, the final visual acuity was compared with the OTS predicted visual acuity.

\section{Statistical analysis}

Data entry, processing and statistical analysis of result was completed using SPSS software Version 20.0. Fisher's exact test was used to compare categorical distribution of visual acuity in patient with or without various risk factors. Z-test for proportion was used for comparison of categorical distribution of final visual acuity with the OTS predicted visual acuity. McNemar's Chi-square test was used to compare categorical distribution of final visual acuity with the presenting visual acuity. $\mathrm{P}$ values less than 0.05 were considered statistically significant.

\section{Results}

\section{Epidemiology}

Between March 2016- March 2017, a total of 95 patients presented with OGI. Twenty-three patients meeting various exclusion criteria were excluded from the study. Seventy-three eyes of 72 patients meeting inclusion criteria were included in the study cohort. Majority of the patients $(55,76 \%)$ were male and mean age was $26.17 \pm$ 19.12 years (min: 5 , max: 80, median 23.50). Distribution according to occupation and geographic location is given in Table 1.

\section{Pattern of ocular trauma}

The majority of patients $(58,81 \%)$ presented to the emergency department with a complaint of diminished vision. Right eye (40, $55 \%$ ) was affected more frequently than the left eye. Most injuries were caused by accidents at home $(29,40 \%)$, with vegetative matters $(17,23 \%)$ being the most common causative agent. Thirty-seven
Table 1 Demographic profile of patients included in study

\begin{tabular}{|c|c|c|c|}
\hline Parameters & Frequency (\%) & Male & Female \\
\hline \multicolumn{4}{|l|}{ Age (years) } \\
\hline $5-10$ & $19(26)$ & 11 & 8 \\
\hline $11-20$ & $13(18)$ & 10 & 3 \\
\hline $21-30$ & $14(19)$ & 12 & 2 \\
\hline $31-40$ & $10(14)$ & 9 & 1 \\
\hline $41-50$ & $10(14)$ & 8 & 2 \\
\hline $51-60$ & $2(3)$ & 2 & 0 \\
\hline $61-70$ & $2(3)$ & 1 & 1 \\
\hline $71-80$ & $2(3)$ & 2 & 0 \\
\hline \multicolumn{4}{|l|}{ Occupation } \\
\hline Student & $28(38)$ & 20 & 8 \\
\hline Farmer & $8(11)$ & 8 & 0 \\
\hline Carpenter & $5(7)$ & 5 & 0 \\
\hline Service & $5(7)$ & 5 & 0 \\
\hline Unemployed & $7(10)$ & 3 & 5 \\
\hline Metal worker & $4(6)$ & 4 & 0 \\
\hline Other & $14(18)$ & 10 & 1 \\
\hline \multicolumn{4}{|l|}{ Geographic distribution } \\
\hline Hilly region & $60(83)$ & 46 & 14 \\
\hline Terai (lowland) regions & $12(17)$ & 9 & 3 \\
\hline
\end{tabular}

Largest number of patients belonged to age group of 5-10 years. Most of them were students and belonged to Hilly region of the country

eyes $(51 \%)$ had injuries involving Zone I, while 20 eyes $(27 \%)$ and 16 eyes (22\%) had Zone II and Zone III injuries respectively [Table 2]. Thirty patients $(41 \%)$ presented within 6 hours of sustaining injury, while time to presentation was $6-24$ hours in 23 patients (32\%), 1 day to 1 week in 15 patients $(21 \%)$, and $>1$ week in 4 patients $(6 \%)$. A total of 65 patients $(90 \%)$ were managed surgically, with 20 patients $(27 \%)$ within 6 hours of presentation, 38 patients $(53 \%)$ in $6-24$ hours, and 7 patients $(10 \%)$ at more than 24 hours. Of the 72 patients, 50 patients $(68 \%)$ received an intravitreal injection of Ceftazidime, Vancomycin and Dexamethasone, while 7 patients $(10 \%)$ received no surgical management.

Among the 73 eyes, 23 (32\%) had hyphema in the anterior chamber and 36 (49\%) had lens injury. A total of 10 eyes $(14 \%)$ had a retained intraocular foreign body. Out of 73 eyes, $9(12 \%)$ had a ruptured globe, $9(12 \%)$ presented with or developed endophthalmitis, 7 cases (10\%) exhibited retinal detachment, and there was one case of a perforated globe.

\section{Ocular examination and OTS}

Visual acuity of patients at presentation and the final visual acuity attended at end of 3 months is summarized in Fig. 1. A total 56 cases (77\%) had visual acuity less than $3 / 60$ on presentation, whereas 10 cases $(15 \%)$ had $6 / 12$ 
Table 2 Patterns of ocular trauma

\begin{tabular}{|c|c|c|c|}
\hline Parameters & Frequency (\%) & Male & Female \\
\hline \multicolumn{4}{|l|}{ Affected eye } \\
\hline Right & $40(56)$ & 31 & 9 \\
\hline Left & $31(43)$ & 23 & 8 \\
\hline Bilateral & $1(1)$ & 1 & 0 \\
\hline \multicolumn{4}{|l|}{ Zones of involvement } \\
\hline Zone I & $37(51)$ & 29 & 8 \\
\hline Zone II & $20(27)$ & 12 & 8 \\
\hline Zone III & $16(22)$ & $14(1)^{\mathrm{a}}$ & 1 \\
\hline \multicolumn{4}{|l|}{ Mode of presentation } \\
\hline Emergency & $58(81)$ & 44 & 14 \\
\hline OPD & $14(19)$ & 11 & 3 \\
\hline \multicolumn{4}{|l|}{ Place of trauma } \\
\hline Home & $29(40)$ & 21 & 8 \\
\hline Field & $13(18)$ & 11 & 2 \\
\hline Road & $10(14)$ & 10 & 0 \\
\hline School & $10(14)$ & 6 & 4 \\
\hline Workshop & $5(7)$ & 4 & 1 \\
\hline Jungle/Garden & $4(6)$ & 2 & 2 \\
\hline Shop & $1(1)$ & 1 & 0 \\
\hline \multicolumn{4}{|l|}{ Agent of trauma } \\
\hline Plant (vegetative material) & $17(23)$ & $7(1)^{a}$ & 9 \\
\hline Metal/Nails & $15(21)$ & 14 & 1 \\
\hline Sharp object & $12(16)$ & 10 & 2 \\
\hline Projectile & $11(15)$ & 8 & 3 \\
\hline Furniture/Appliances & $8(11)$ & 7 & 1 \\
\hline Blunt object & $7(10)$ & 7 & 0 \\
\hline Body part & $3(4)$ & 2 & 1 \\
\hline \multicolumn{4}{|l|}{ Chief complaint } \\
\hline Diminution of vision & $45(61)$ & 35 & 10 \\
\hline Ocular pain & $21(29)$ & 17 & 4 \\
\hline Swelling of eye & $4(7)$ & 2 & 2 \\
\hline Inability to open eye & $2(3)$ & 1 & 1 \\
\hline \multicolumn{4}{|l|}{ Mode of trauma } \\
\hline Accident & $58(80)$ & 45 & 13 \\
\hline Physical assault & $3(4)$ & 2 & 1 \\
\hline Inadvertent & $6(9)$ & 3 & 3 \\
\hline RTA & $5(7)$ & 5 & 0 \\
\hline
\end{tabular}

OPD Outpatient department, RTA Road traffic accident

${ }^{\mathrm{a} B i l a t e r a l ~ e y e ~ i n v o l v e m e n t ~ o f ~ a ~ s i n g l e ~ p e r s o n ~}$

or more. A McNemar's Chi-squared test was applied to compare visual acuity at presentation and after three months with a statistically significant relationship [Table 3]. When a cross tab correlation analysis was done, $57.1 \%$ of cases (8 eyes) with an initial VA of NPL had a final VA of NPL, while $90 \%$ of cases (9 eyes) maintained a VA of $6 / 12$ or better.

After calculating the final OTS score, patients were categorized into five OTS groups and final visual acuity was assessed. Most cases (31, 42 \%) fell into OTS Group 3, followed by Group 2 (18, $25 \%)$. Group 1, 4, and 5 each had 8 cases (11\%). After three months, 21 eyes $(29 \%)$ achieved a visual acuity of $6 / 12$ or better.

\section{Correlation analysis}

Evaluation of various risk factors for poor final visual acuity was completed [Table 3]. A Fisher's exact test applied to compare zones of involvement with final VA was statistically significant with a p-value of 0.001 . A total of 9 eyes $(56.3 \%)$ with zone III involvement had a final VA of HM or less. While VA of HM or less was found in 8 eyes $(21.6 \%)$ and 7 eyes $(35 \%)$ in patients with zones I and II involvement, respectively. The presence of a globe rupture was significantly associated with poor visual outcome when compared to non-ruptured globes $(p=0.001)$, where 8 eyes $(88.8 \%)$ with ruptured globes resulted in a VA of HM or worse compared to non-ruptured globes (16 eyes, $25 \%$ ). For patients with endophthalmitis, 7 eyes $(77.8 \%)$, had a final VA of HM or worse compared to 17 eyes $(26.6 \%)$ without endophthalmitis $(p=0.001)$. Twenty eyes $(40 \%)$ receiving intravitreal injections of antibiotics had a final VA of HM or worse, while those without injections had a VA of HM or worse in 4 eyes (17.4\%). A statistically significant relationship between time to presentation and final VA was found with a p-value of 0.001 . A total of 15 patients (50\%) had a final VA of $6 / 12$ or better when they presented within 6 hours of injury, while 3 patients (15.8\%), who presented after more than 2 days, had a final VA of $6 / 12$ or better.

Analysis of actual final VA compared to predicted final VA based on OTS group was done using Z test for proportion. It was applied manually to each of the categories to test for the statistically significant dissimilarity. Fifteen of the 25 categories of OTS groups had a final VA with no statistically significant difference compared to the predicted outcome $(p>0.05)$ [Table 4].

\section{Discussion}

This study describes the profile of open globe injuries presenting to a tertiary hospital in Nepal and evaluates the use of the OTS in predicting visual outcomes. The patterns of ocular trauma and demographic profile of patients found in this study closely matched to studies of ocular trauma worldwide [10, 11, 23-25]. Our study found that a large portion of the patients, about one fourth, were below the age of 10 . Hence, denoting the involvement of vulnerable population. However, it must also be noted that second largest age group were 


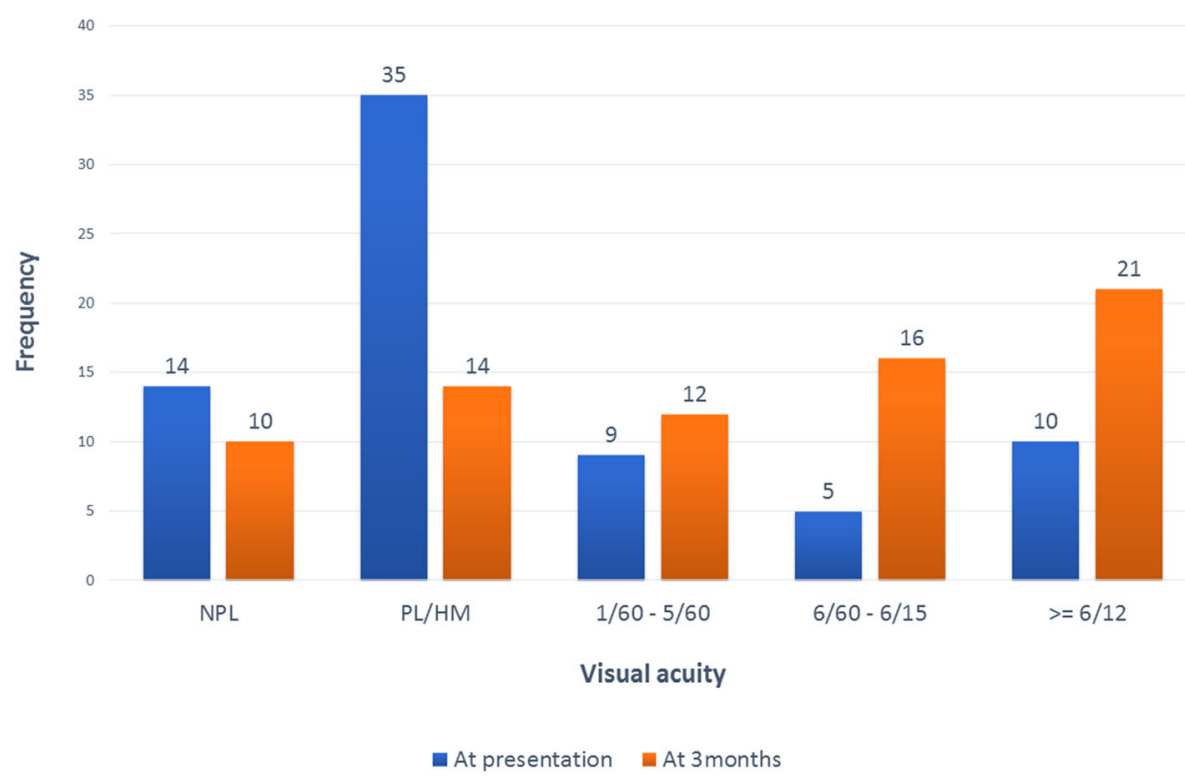

Fig. 1 Bar diagram showing Visual acuity at presentation and at 3-month follow-up. Majority of patients presented with initial visual acuity less than $1 / 60$, while majority of patients had visual acuity of more than $6 / 60$ at the end of 3 months follow up. NPL No light perception, PL Perception of light, HM Hand movements

between 2nd to 3rd decade of life, this may be due larger risk faced by this age group during their line of work or their frequent social activities. This correlates with the occupational distribution of patients, with more than one third being students. This study also shows the preponderance of male gender for ocular trauma. This may be explained by the fact that male population tend have more outdoor activities and have higher tendencies to face occupational hazards. Most patients were from the hilly region of Nepal, with the majority being from the urban city of Kathmandu, showing the influence of location and awareness to seek ophthalmic care.

Causative agent and mode of trauma often depend on location of a study. Similar to other studies in the rural region, the most common agent of injury was vegetative material such as sticks and branches, followed by metal; however, this is in contrast to many western studies that reported blunt objects as the most common causative agent $[8,25-27]$. Accidental trauma was most common, followed by inadvertent trauma. Comparatively, studies conducted in larger urban areas of developed countries have shown assault (41\%) as the most common cause of ocular trauma [28].

Many of the variables analyzed showed a statistically significant correlation with final visual outcomes, including zone of involvement and time to presentation. The most common location of open globe injury in this population was a Zone I injury; however, more posterior injuries carried a worse prognosis similar to findings in other studies [29-31]. In general, final VA decreased as the time to presentation after trauma increased. Among the patients who presented less than 6 hours after the injury, $50 \%$ had a final VA of $6 / 12$ or better compared to $15.8 \%$ of patients presenting after two days. Previous studies have also shown evidence that final visual outcome is affected by time to presentation or repair [32, 33]. However, some studies have also concluded that there may not be considerable difference in prognosis for eyes receiving early or delayed treatment [34]. In this study, it was found that initial visual acuity, extent of injury, need for intravitreal injection, development of endophthalmitis, and a ruptured globe were all predictive of a poorer final visual acuity.

When the OTS-predicted visual acuity was compared to the actual final visual acuity for each group, it was found that there was no statistically significant difference for 15 of the 25 categories, resulting in a $60 \%$ predictive accuracy of the OTS for patients at 3 months. This is comparable to a $77 \%$ predictive value for the OTS at 6 months in the study by Kuhn et al. [18]. The variations in Groups 1-4 captured worse outcomes than predicted, while Group 5 showed better outcomes. This may be due to the shorter follow up time that fails to reliably capture the final visual outcomes of the injured eye.

The use of the OTS in general, pediatric, weaponrelated eye injuries to predict visual outcomes has been evaluated in numerous studies in North America, Europe, and Asia [4, 18, 35-38]. This is the first study in a Nepalese population and highlights both the scope of open globe injury in the Nepal and the utility of the OTS for the prediction of visual outcomes and management of patients with open globe injury. 
Table 3 Comparison of categorical distribution of visual acuity at 3-month follow-up with various risk factors

\begin{tabular}{|c|c|c|c|c|c|c|c|c|}
\hline Parameters & $\begin{array}{l}\text { VA at } 3 \\
\text { months }\end{array}$ & $\begin{array}{l}\text { NPL } \\
\text { No. (\%) }\end{array}$ & $\begin{array}{l}\text { PL/ HM } \\
\text { No. (\%) }\end{array}$ & $\begin{array}{l}1 / 60-5 / 60 \\
\text { No. (\%) }\end{array}$ & $\begin{array}{l}6 / 60-6 / 15 \\
\text { No. (\%) }\end{array}$ & $\begin{array}{l}>=6 / 12 \\
\text { No. (\%) }\end{array}$ & $\begin{array}{l}\text { Total } \\
\text { No. (\%) }\end{array}$ & $p$ value \\
\hline \multirow[t]{6}{*}{ VA at presentation } & NPL & $8(57.1)$ & $3(21.4)$ & $1(7.1)$ & $2(14.3)$ & $0(0)$ & $14(100)$ & $<0.001^{a}$ \\
\hline & $\mathrm{PL} / \mathrm{HM}$ & $2(5.7)$ & $11(31.4)$ & $11(31.4)$ & $6(17.1)$ & $5(14.3)$ & $35(100)$ & \\
\hline & $1 / 60-5 / 60$ & $0(0)$ & $0(0)$ & $0(0)$ & $5(55.6)$ & $4(44.4)$ & $9(100)$ & \\
\hline & $6 / 60-6 / 15$ & $0(0)$ & $0(0)$ & $0(0)$ & $2(40)$ & $3(60)$ & $5(100)$ & \\
\hline & $>=6 / 12$ & $0(0)$ & $0(0)$ & $0(0)$ & $1(10)$ & $9(90)$ & 10(100) & \\
\hline & Total & $10(13.7)$ & $14(19.2)$ & $12(16.4)$ & $16(21.9)$ & $21(28.8)$ & $73(100)$ & \\
\hline \multirow[t]{4}{*}{ Zones of injury } & Zone I & $5(13.5)$ & $3(8.1)$ & $3(8.1)$ & $10(27)$ & $16(43.2)$ & $37(100)$ & $0.001^{b}$ \\
\hline & Zone II & $0(0)$ & $7(35)$ & $5(25)$ & $5(25)$ & $3(15)$ & $20(100)$ & \\
\hline & Zone III & $5(31.3)$ & $4(25)$ & $4(25)$ & $1(6.3)$ & $2(12.5)$ & $16(100)$ & \\
\hline & Total & 10(13.7) & 14(19.2) & $12(16.4)$ & $16(21.9)$ & $21(28.8)$ & 73(100) & \\
\hline \multirow[t]{3}{*}{ Ruptured globes } & Present & $4(44.4)$ & $4(44.4)$ & $1(11.1)$ & $0(0)$ & $0(0)$ & $9(100)$ & $0.001^{b}$ \\
\hline & Absent & $6(9.4)$ & 10(15.6) & $11(17.2)$ & $16(25)$ & 21(32.8) & $64(100)$ & \\
\hline & Total & $10(13.7)$ & 14(19.2) & $12(16.4)$ & 16(21.9) & $21(28.8)$ & $73(100)$ & \\
\hline \multirow[t]{3}{*}{ Endophthalmitis } & Present & $6(66.7)$ & $1(11.1)$ & $1(11.1)$ & $1(11.1)$ & $0(0)$ & $9(100)$ & $0.001^{b}$ \\
\hline & Absent & $4(6.3)$ & $13(20.3)$ & $11(17.2)$ & 15(23.4) & $21(32.8)$ & $64(100)$ & \\
\hline & Total & 10(13.7) & 14(19.2) & $12(16.4)$ & 16(21.9) & $21(28.8)$ & $73(100)$ & \\
\hline \multirow[t]{3}{*}{ Intra vitreal injections } & Yes & $8(16)$ & $12(24)$ & $9(18)$ & $13(26)$ & $8(16)$ & $50(100)$ & $0.013^{b}$ \\
\hline & No & $2(8.7)$ & $2(8.7)$ & $3(13)$ & $3(13)$ & $13(56.5)$ & $23(100)$ & \\
\hline & Total & $10(13.7)$ & $14(19.2)$ & $12(16.4)$ & $16(21.9)$ & $21(28.8)$ & $73(100)$ & \\
\hline \multirow[t]{4}{*}{ Time to presentation } & $<6$ hours & $0(0)$ & $5(16.7)$ & $6(20)$ & $4(13.3)$ & $15(50)$ & $30(100)$ & $0.001^{b}$ \\
\hline & $6-24$ hours & $3(13)$ & $4(17.4)$ & $4(17.4)$ & $9(39.1)$ & $3(13)$ & $23(100)$ & \\
\hline & $>2$ days & $7(36.84)$ & $25(26.31)$ & $2(10.52)$ & $2(10.52)$ & $3(15.78)$ & $19(100)$ & \\
\hline & Total & $10(13.7)$ & $14(19.2)$ & $12(16.4)$ & $16(21.9)$ & $21(28.8)$ & $73(100)$ & \\
\hline
\end{tabular}

VA Visual acuity, NPL No light perception, LP Light perception, HM Hand movements

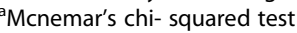

Fisher's exact test

One limitation of this study is its scope at a single hospital, which may not capture the trends of the entire population with diverse geographical settings. Further multicenter studies need to be done to better evaluate the scope of ocular injury in Nepal and utilization of the OTS in open globe injury.

\section{Conclusions}

We found that open globe injuries presenting with poor visual acuity, delayed presentation, posterior zones of injury, need for intravitreal injections, endophthalmitis, and globe rupture are associated with poorer prognosis. OTS can be an accurate predictive tool for estimating

Table 4 OTS predicted visual outcome and comparison to final visual outcome

\begin{tabular}{|c|c|c|c|c|c|c|c|c|c|c|c|c|c|c|c|}
\hline \multirow{2}{*}{$\begin{array}{l}\text { OTS } \\
\text { Group }\end{array}$} & \multicolumn{3}{|l|}{ NPL } & \multicolumn{3}{|c|}{ LP/HM } & \multicolumn{3}{|c|}{$1 / 60-5 / 60$} & \multicolumn{3}{|c|}{$6 / 60-6 / 15$} & \multicolumn{3}{|c|}{$>=6 / 12$} \\
\hline & $\begin{array}{l}\text { OTS } \\
{[\%]}\end{array}$ & $\begin{array}{l}\text { Final } \\
\text { [\%] }\end{array}$ & $\begin{array}{l}p^{*} \\
\text { value }\end{array}$ & $\begin{array}{l}\text { OTS } \\
\text { [\%] }\end{array}$ & $\begin{array}{l}\text { Final } \\
\text { [\%] }\end{array}$ & $\begin{array}{l}p^{*} \\
\text { value }\end{array}$ & $\begin{array}{l}\text { OTS } \\
\text { [\%] }\end{array}$ & $\begin{array}{l}\text { Final } \\
\text { [\%] }\end{array}$ & $\begin{array}{l}p^{*} \\
\text { value }\end{array}$ & $\begin{array}{l}\text { OTS } \\
\text { [\%] }\end{array}$ & $\begin{array}{l}\text { Final } \\
\text { [\%] }\end{array}$ & $\begin{array}{l}p^{*} \\
\text { value }\end{array}$ & $\begin{array}{l}\text { OTS } \\
\text { [\%] }\end{array}$ & $\begin{array}{l}\text { Final } \\
\text { [\%] }\end{array}$ & $\begin{array}{l}p^{*} \\
\text { value }\end{array}$ \\
\hline 1 & 74 & 75 & $>0.05$ & 15 & 25 & $<0.05$ & 7 & 0 & $<0.05$ & 3 & 0 & $>0.05$ & 1 & 0 & $>0.05$ \\
\hline 2 & 27 & 22.2 & $>0.05$ & 26 & 38.9 & $<0.05$ & 18 & 27.8 & $<0.05$ & 15 & 11.1 & $>0.05$ & 15 & 0 & $<0.05$ \\
\hline 3 & 2 & 0 & $>0.05$ & 11 & 16.1 & $>0.05$ & 15 & 22.6 & $>0.05$ & 31 & 32.3 & $>0.05$ & 41 & 29 & $<0.05$ \\
\hline 4 & 1 & 0 & $>0.05$ & 2 & 0 & $>0.05$ & 3 & 0 & $>0.05$ & 22 & 50 & $<0.05$ & 73 & 50 & $<0.05$ \\
\hline 5 & 0 & 0 & $>0.05$ & 1 & 0 & $>0.05$ & 1 & 0 & $>0.05$ & 5 & 0 & $<0.05$ & 94 & 100 & $<0.05$ \\
\hline
\end{tabular}


final visual acuity even for a short follow up period of 3 months. It provides a better means for patient counseling and aids in clinical decision making; thus, OTS can be a valuable standard predictive tool for management of OGI specially in a resource limited setting of a developing country like Nepal.

\author{
Abbreviations \\ OGI: Open globe injuries; OTS: Ocular trauma score; VA: Visual acuity; \\ BPKLCOS: B.P. Koirala Lions Centre for Ophthalmic Studies; \\ BETTS: Birmingham Eye Trauma Terminology System; RAPD: Relative afferent \\ pupillary defect; RD: Retinal detachment; TUTH: Tribhuvan University \\ Teaching Hospital; NPL: No perception of light; PL: Perception of light; \\ CF: Counting fingers
}

\section{Acknowledgements}

Not applicable.

\section{Disclaimer}

The view(s) expressed herein are those of the author(s) and do not reflect the official policy or position of Brooke Army Medical Center, the U.S. Army Medical Department, the U.S. Army Office of the Surgeon General, the Department of the Air Force, the Department of the Army, Department of Defense, the Uniformed Services University of the Health Sciences or any other agency of the U.S. Government.

\section{Authors' contributions}

SMS, MT, JBS: Conceptualization and design of the study; SMS: acquisition, analysis and interpretation of data; SMS, CLA, GAJ: drafting the manuscript; GAJ, AK, AKH, RA: data analysis, statistical support and revision of the manuscript for important intellectual content. All authors read and approved the final manuscript.

\section{Funding}

The authors declare no funding was received for this study.

\section{Availability of data and materials}

The datasets used and/or analyzed during the current study are available from the corresponding author on reasonable request.

\section{Ethics approval and consent to participate}

Ethical Approval for the study was taken from the Institutional Review Board of the Institute of Medicine, Tribhuvan University Teaching Hospital. [Ref. no: 299(6-11-E)2/72/73]. The study was performed in accordance with the ethical standards as laid down in the 1964 Declaration of Helsinki and its later amendments or comparable ethical standards. Written consent was obtained from all of the patients before each treatment applied in the study. Parental consent was obtained for patients under the age of 16

\section{Consent for publication}

Not applicable.

\section{Competing interests}

The authors declare that they have no competing interests.

\section{Author details}

'B.P. Koirala Lions Centre for Ophthalmic Studies, Institute of Medicine, Tribhuvan University Teaching Hospital, Kathmandu, Nepal. ${ }^{2}$ Department of Vitreoretina, Mechi Eye Hospital, Birtamode, Nepal. ${ }^{3}$ School of Medicine, Emory University, Atlanta, GA, USA. ${ }^{4}$ Department of Ophthalmology, Brooke Army Medical Center, San Antonio, TX, USA. ${ }^{5}$ Department of Surgery, Uniformed Services University of the Health Science, Bethesda, MD, USA. ${ }^{6}$ Department of Vitreoretinal services, Birat Eye Hospital, Biratnagar, Nepal. ${ }^{7}$ Department of Ophthalmology, Birat Medical College and Teaching Hospital, Biratngar, Nepal. ${ }^{8}$ Save Sight Institute, University of Sydney, Sydney, Australia. 'ions Eye Institute, University of Western Australia, Perth, Australia. ${ }^{10}$ National Healthcare Group Eye Institute, Tan Tock Seng Hospital, Singapore, Singapore. ${ }^{11}$ Singapore Eye Research Institute, Singapore, Singapore.

${ }^{12}$ Moorfields Eye Hospital, NHS Foundation Trust, London, UK.
Received: 26 September 2020 Accepted: 17 January 2021

Published online: 04 February 2021

\section{References}

1. Parver LM. Eye trauma. The neglected disorder. Arch Ophthalmol. 1986; 104(10):1452-3.

2. Brandt MT, Haug RH. Traumatic hyphema: a comprehensive review. J Oral Maxillofac Surg. 2001;59(12):1462-70.

3. Négrel AD, Thylefors B. The global impact of eye injuries. Ophthalmic Epidemiol. 1998;5(3):143-69.

4. Man CYW, Steel D. Visual outcome after open globe injury: a comparison of two prognostic models - the Ocular Trauma Score and the Classification and Regression Tree. Eye. 2009:24(1):84-9.

5. Brilliant LB, Pokhrel RP, Grasset NC, Lepkowski JM, Kolstad A, Hawks W, Pararajasegaram R, Brilliant GE, Gilbert S, Shrestha SR, et al. Epidemiology of blindness in Nepal. Bull World Health Organ. 1985;63(2):375-86.

6. Schein OD, Hibberd PL, Shingleton BJ, Kunzweiler T, Frambach DA, Seddon $J M$, et al. The spectrum and burden of ocular injury. Ophthalmology. 1988; 95(3):300-5

7. Khatry SK. The epidemiology of ocular trauma in rural Nepal. Br J Ophthalmol. 2004;88(4):456-60

8. Kuhn F, Mester V, Berta A, Morris R. Epidemiology of serious ocular trauma. The United States Eye Injury Registry (USEIR) and the Hungarian Eye Injury Registry (HEIR). Der Ophthalmologe. 1998;95(5):332-43.

9. McGwin G. Incidence of emergency department-treated eye injury in the United States. Arch Ophthalmol. 2005:123(5):662.

10. Schrader WF. Epidemiology of open globe eye injuries: analysis of 1026 cases in 18 years. Klin Monbl Augenheilkd. 2004:221(8):629-35.

11. Li X, Zarbin MA, Bhagat N. Pediatric open globe injury: a review of the literature. J Emerg Trauma Shock. 2015;8(4):216-23. https://doi.org/10.4103/ 0974-2700.166663.

12. Barr CC. Prognostic factors in corneoscleral lacerations. Arch Ophthalmol. 1983:101(6):919-24.

13. Chiquet C, Zech JC, Gain P, Adeleine P, Trepsat C. Visual outcome and prognostic factors after magnetic extraction of posterior segment foreign bodies in 40 cases. Br J Ophthalmol. 1998;82(7):801-6.

14. Edmund J. The prognosis of perforating eye injuries. Acta Ophthalmo (Copenh). 1968;46(6):1165-74.

15. Sternberg $P$, Juan Ed, Michels RG, Auer C. Multivariate analysis of prognostic factors in penetrating ocular injuries. Am J Ophthalmol. 1984;98(4):467-72.

16. Kuhn F, Morris R, Witherspoon CD, Heimann K, Jeffers JB, Treister G. A standardized classification of ocular trauma. Ophthalmology. 1996;103(2): 240-3.

17. Kuhn F, Morris R, Witherspoon CD, Mester V. The Birmingham Eye Trauma Terminology system (BETT). J Fr Ophtalmol. 2004;27(2):206-10.

18. Kuhn F, Maisiak R, Mann L, Mester V, Morris R, Witherspoon C. The ocular trauma score (OTS). Ophthalmol Clin North Am. 2002;15(2):163-5.

19. Fujikawa A, Mohamed $\mathrm{YH}$, Kinoshita $H$, Matsumoto M, Uematsu M, Tsuiki $E$, et al. Visual outcomes and prognostic factors in open-globe injuries. BMC Ophthalmol. 2018:18(1):138.

20. Murray DC. Implementing and applying the ocular trauma score: the challenges. Community Eye Health. 2015;28(91):45.

21. Scott R. The ocular trauma score. Community Eye Health. 2015;28(91):44-5.

22. Pieramici DJ, Sternberg P, Aaberg TM, Bridges WZ, Capone A, Cardillo JA, et al. A system for classifying mechanical injuries of the eye (globe). Am J Ophthalmol. 1997:123(6):820-31.

23. Kinderan $\mathrm{W}$, Shrestha E, Maharjan IM, Karmacharya S. Pattern of ocular trauma in the Western Region of Nepal. Nepal J Ophthalmol. 2012:4(1):5-9.

24. Batur M, Seven E, Esmer O, Akaltun MN, Yasar T, Cinal A. Epidemiology of adult open globe injury. J Craniofac Surg. 2016;27(7):1636-41.

25. May DR, Kuhn FP, Morris RE, Witherspoon CD, Danis RP, Matthews GP, et al. The epidemiology of serious eye injuries from the United States Eye Injury Registry. Graefes Arch Clin Exp Ophthalmol. 2000;238(2):153-7.

26. Shah M, Shah S, Khandekar R. Ocular injuries and visual status before and after their management in the tribal areas of Western India-A historical cohort study. Graefes Arch Clin Exp Ophthalmol. 2007;246(2):191-7.

27. Ojabo CO, Malu KN, Adeniyi OS. Open globe injuries in Nigerian children: epidemiological characteristics, etiological factors, and visual outcome. Middle East Afr J Ophthalmol. 2015;22(1):69-73. doi:https://doi.org/10.4103/ 0974-9233.148352 
28. Liggett PE, Pince KJ, Barlow W, Ragen M, Ryan SJ. Ocular trauma in an urban population. Ophthalmology. 1990;97(5):581-4.

29. Gillbert CM, Soong HK, Hirst LW. A two-year prospective study of penetrating ocular trauma at the Wilmer Ophthalmological Institute. Ann Ophthalmol. 1987;19(3):104-6.

30. Groess S, Nanda SK, Mieler WF. Assault-related penetrating ocular injury. Am J Ophthalmol. 1993;116(1):26-33.

31. Pieramici DJ, Eong K-GA, Sternberg P, Marsh MJ. The prognostic significance of a system for classifying mechanical injuries of the eye (globe) in openglobe injuries. J Trauma. 2003;54(4):750-4.

32. Blanch RJ, Bishop J, Javidi H, Murray PI. Effect of time to primary repair on final visual outcome after open globe injury. Br J Ophthalmol. 2019;103(10): $1491-4$.

33. Ahmed Y, Schimel AM, Pathengay A, Colyer MH, Flynn HW. Jr. Endophthalmitis following open-globe injuries. Eye. 2012;26(2):212-7.

34. Hernandez DM, Gomez VL. [Ocular trauma score comparison with open globe receiving early or late care attention]. Cir Cir. 2015;83(1):9-14.

35. Agrawal $\mathrm{R}$, Wei $\mathrm{H}$, Teoh $\mathrm{S}$. Prognostic factors for open globe injuries and correlation of ocular trauma score at a tertiary referral eye care centre in Singapore. Indian J Ophthalmol. 2013;61(9):502.

36. Shah MA, Shah SM, Applewar A, Patel C, Shah S, Patel U. Ocular trauma score: a useful predictor of visual outcome at six weeks in patients with traumatic cataract. Ophthalmology. 2012;119(7):1336-41.

37. Unver YB, Kapran Z, Acar N, Altan T. Ocular trauma score in open-globe injuries. J Trauma. 2009;66(4):1030-2.

38. Uysal Y, Mutlu FM, Sobac G. Ocular trauma score in childhood open-globe injuries. J Trauma. 2008;65(6):1284-6.

\section{Publisher's Note}

Springer Nature remains neutral with regard to jurisdictional claims in published maps and institutional affiliations.

Ready to submit your research? Choose BMC and benefit from:

- fast, convenient online submission

- thorough peer review by experienced researchers in your field

- rapid publication on acceptance

- support for research data, including large and complex data types

- gold Open Access which fosters wider collaboration and increased citations

- maximum visibility for your research: over $100 \mathrm{M}$ website views per year

At $\mathrm{BMC}$, research is always in progress.

Learn more biomedcentral.com/submissions 